\title{
Manutenção preventiva corretiva em edificações: uma revisão de literatura
}

A manutenção das edificações constitui-se de ações direcionadas aos elementos construtivos, equipamentos e instalações que formam todo o conjunto de um edifício e que proporcionam segurança, habitabilidade e eficiência proveniente de um projeto onde a execução e os materiais empregados terão maior vida útil decorrente da maneira de utilização. Assim, este trabalho teve como objetivo realizar uma revisão de literatura a respeito da importância da manutenção preventiva e corretiva em edificações. A metodologia utilizada para atingir o objetivo proposto foi a revisão de literatura. A pesquisa foi do tipo descritiva de abordagem qualitativa. A amostra desta revisão de literatura foi composta por monografias, dissertações, normas, artigos com publicações nacionais e data de publicação compreendida entre os últimos sete anos. A base de dados para levantamento dos artigos foi o Google Acadêmico. Os resultados demonstraram que a manutenção se caracteriza por um fluxo constante de serviços padronizados e periódicos, como: limpeza, lavagem, consertos, adequações, dentre outros. Ao final concluiu-se que a manutenção preventiva é um tipo de manutenção onde as ações são previamente planejadas e a manutenção corretiva é realizada por meio de ações não planejadas, de maneira imediata, e tem como objetivo restaurar a capacidade funcional dos equipamentos ou dos sistemas que estão com problema.

Palavras-chave: Corretiva; Edificações; Manutenção; Preventiva.

\section{Corrective preventive maintenance in buildings: a literature review}

The maintenance of buildings consists of actions directed at the construction elements, equipment and installations that form the whole of a building and that provide security, habitability and efficiency resulting from a project where the execution and the materials used will have a longer useful life resulting from the way of use. Thus, this study aimed to conduct a literature review regarding the importance of preventive and corrective maintenance in buildings. The methodology used to achieve the proposed objective was the literature review. The research was of the descriptive type of qualitative approach. The sample of this literature review was composed of monographs, dissertations, rules, articles with national publications and date of publication between the last seven years. The database for collecting the articles was Google Scholar. The results showed that maintenance is characterized by a constant flow of standardized and periodic services, such as: cleaning, washing, repairs, adjustments, among others. In the end, it was concluded that preventive maintenance is a type of maintenance where actions are previously planned and corrective maintenance is performed through unplanned actions, in an immediate manner, and aims to restore the functional capacity of equipment or systems who are in trouble.

Keywords: Corrective; Buildings; Maintenance; Preventive.

Topic: Engenharia Civil

Reviewed anonymously in the process of blind peer
Received: 10/04/2020

Approved: 21/07/2020

Gustavo Henrique Costa Mariano

Faculdade Presidente Antônio Carlos, Brasil

http://lattes.cnpq.br/4344083707774282

http://orcid.org/0000-0001-5488-1614

gustavo_costamariano@hotmail.com

Referencing this:

MARIANO, G. H. C.. Manutenção preventiva corretiva em edificações: uma revisão de literatura. Engineering Sciences, v.8, n.2, p.10-17, 2020. DOI: http://doi.org/10.6008/CBPC2318-3055.2020.002.0002 


\section{INTRODUÇÃO}

A Associação Brasileira de Normas Técnicas (ABNT) por meio da NBR-5674 normatiza a manutenção de edificações e destaca que a manutenção é um assunto que vem crescendo no setor da construção civil, deixando de limitar o processo de construção somente até o momento de entrega da edificação ao seu proprietário. A norma destaca que as edificações possuem um valor social fundamental, apresentam características como: "são construídas para atender aos usuários durante muitos anos, e ao longo deste tempo de serviço devem apresentar condições adequadas ao uso que se destinam, resistindo aos agentes ambientais e de uso que alteram suas propriedades técnicas iniciais" (ABNT, 2012).

As edificações possuem diversas finalidades, como comércio, habitação, indústria e serviços que, com o decorrer do tempo, necessitam de manutenção adequada para se manterem em pleno funcionamento de maneira segura e agradável, livre de manifestações patológicas, como infiltração, mofo e bolor, eflorescência e criptoflorescência, corrosão de armaduras, fissuras e trincas (DONATO et al., 2019). Todos estes problemas ocasionados pela falta de manutenção provocam nas edificações um declínio na duração física da obra, além de comprometer os fatores estéticos, social, segurança e econômico (SANTOS, 2017).

Desta maneira, a manutenção nas edificações tem como intenção restaurar e/ou substituir partes danificadas da obra, deixando-a em condições favorável de desempenho, além de proporcionar que a mesma volte a cumprir com suas funções iniciais (CRUZ et al., 2017). Para normatizar e direcionar as ações de manutenção em edificações existem diversas normas, como: NBR: 5674, segunda edição de 25 julho de 2012 - "Manutenção de Edificações - Requisitos para o sistema de gestão de manutenção"; NBR: 14037, segunda edição de 28 julho de 2011 - "Diretrizes para elaboração de manuais de uso, operação e manutenção das edificações - Requisitos para elaboração e apresentação dos conteúdos"; NBR: 15575 de 2013 - "Edificações habitacionais - Desempenho"; NBR: 16280, primeira edição 18 março 2014 - "Reforma em edificações Sistema de Gestão de Reformas - Requisitos" (CARDOSO, 2016).

Apesar de não haver uma legislação especifica para a obrigatoriedade da manutenção nas edificações, as normas brasileiras regulamentam as ações de manutenção, além de ressaltarem a importância da mesma. Assim, ressalta-se que a manutenção deve está prevista desde a fase do projeto, atendendo ao período de vida útil pré-estabelecido para a edificação, bem como aos elementos construtivos nela utilizados e por este motivo é importante que as edificações possuam um plano de manutenção para deixá-la sempre em boas condições de uso (SALDANHA, 2017).

Os benefícios ocasionados aos clientes e ao construtor pela execução da manutenção nas edificações são vários, dentre eles está a valorização do imóvel no mercado imobiliário, a garantia de segurança, conforto e otimização do tempo de trabalho (VILLANUEVA, 2015). Desta maneira, o presente artigo tem como objetivo realizar uma revisão de literatura a respeito da importância da manutenção preventiva e corretiva em edificações. 


\section{METODOLOGIA}

A metodologia utilizada na presente pesquisa foi a revisão de literatura, ou seja, foi um estudo secundário uma vez que estabeleceu conclusões a partir de estudos primários. A pesquisa foi do tipo descritiva de abordagem qualitativa. A pesquisa descrita observa, registra e analisa dados (informações), sem manipulá-los. A abordagem qualitativa se preocupa, com as ciências sociais, com um nível de realidade que não pode ser quantificado, apenas analisado e estudado (MINAYO, 2012). A amostra desta revisão de literatura foi composta por monografias, dissertações, normas, artigos com publicações nacionais e data de publicação compreendida entre os últimos sete anos. A base de dados para levantamento dos artigos foi o Google Acadêmico.

\section{DISCUSSÃO TEÓRICA}

\section{Manutenção de Edifícios}

A manutenção de edifícios é algo que deve ser considerado desde a fase inicial dos empreendimentos, ou seja, desde o projeto inicial da obra, ao qual devem ser incluídos mais dois projetos, sendo um para a manutenção e outro da manutenção. O projeto para a manutenção é desenvolvido desde a concepção, desenvolvimento e detalhamento do projeto inicial e devem ser consideradas todas as ações que serão tomadas e que irão contribuir para o aumento do grau de manutenção. Já o projeto da manutenção deve contemplar a fase de construção, operação e uso, e deve prever a definição de programas, procedimentos e periodicidade dos serviços de manutenção, vistorias e substituições (CRUZ et al., 2017).

Segundo a NBR: 5674 para a manutenção de edifícios atingir uma maior eficiência e eficácia a mesma deve ser "fundamentada em procedimentos organizados em um sistema de gestão de manutenção", ou seja, é importante que se desenvolva um plano (projeto) de manutenção (ABNT, 2012). Carreira (2018) ressalta que, mesmo as edificações construídas antes da vigência dessa norma, "devem procurar se adequar ou criar seus programas de manutenção", uma vez que, por meio do programa de manutenção é "possível preservar as características originais da edificação e prevenir a perda de desempenho decorrente da degradação dos seus sistemas".

Em uma pesquisa desenvolvida por Gentili (2018), com o objetivo de enfatizar a importância de uma boa manutenção aliada à presença de uma profissional da área de Engenharia, para assim manter toda a qualidade, funcionalidade e eficiência da estrutura do empreendimento, o autor constatou, na obra pesquisada que a mesma dispunha de um plano de manutenção que era composto por diversos serviços essenciais para manter a funcionalidade e a estética do condomínio, conforme os padrões das normas brasileiras. O autor destacou que, através da aplicabilidade do plano de manutenção, o condomínio conseguiu manter a mesma excelência e qualidade da estrutura da propriedade quando entregue a 14 anos atrás. Em outra pesquisa desenvolvida por Queiroz (2018) que investigou a gestão de manutenção predial da Universidade Federal do Rio Grande do Norte (UFRN), o autor concluiu que a aplicação de um planejamento de gestão, com inspeções prediais periódicas, e programação para as intervenções de manutenção predial, 
evitando que estas interfiram nas atividades diárias do empreendimento é algo que traz um grande benefício, uma vez que evita a ocorrência de situações indesejáveis, como é o caso de problemas com a estrutura física.

A manutenção é uma ferramenta que viabiliza a conservação dos edifícios, maximizando, assim, o seu desempenho, ou seja, a maneira com que determinada edificação se comporta ao ser utilizada frente a algumas condições. As normas de desempenho estão estabelecidas na NBR: 15.575 de 2013. Esta norma tem como foco o atendimento das expectativas dos usuários quanto ao uso das edificações, incluindo a vida útil, funções técnicas e socioeconômicas. Esta norma destaca a importância da realização de manutenção nos edifícios, destacando a influência que as mesmas exercem na garantia e na prolongação da vida útil de projeto. Assim, a vida útil de uma edificação é conceituada pela NBR 15.575 como:

Período de tempo estimado para o qual um edifício e/ou seus sistemas, elementos e componentes são projetados a fim de atender às atividades para as quais foram projetados e construídos considerando: 1- o atendimento dos níveis de desempenho previstos na NBR 15.575 , e 2- a periodicidade e a correta execução dos processos de manutenção especificados no respectivo Manual de Uso, Operação e Manutenção. (ABNT, 2013)

Percebe-se, que segundo a norma, quando não se realiza ações de manutenção, corre-se o risco de não atingir a vida útil de projeto. Assim, destaca-se que a manutenção de edifícios é classificada, segundo a NBR: 5.674 em três tipos, sendo estes: corretiva, preventiva e rotineira (ABNT, 2012). Além dessa classificação, Cruz et al. (2017) acrescenta ainda a manutenção preditiva e a manutenção detectiva. Devido ao foco no tema da pesquisa, logo abaixo é abordado teoricamente as manutenções preventiva e corretiva.

\section{Manutenção Preventiva}

A manutenção pode ser conceituada como a ação realizada para manter, melhorar ou restaurar partes de um edifício para sustentar a utilidade e valor do mesmo. Pode, ainda, ser conceituada como uma combinação de ações técnicas e administrativas que visam restaurar ou substituir algo ao estado que consiga exercer a função original, atingindo um grau satisfatório de desempenho (CAMPOS et al., 2014). Segundo Coelho (2016) a manutenção é norteada por alguns objetivos, sendo estes: garantir que os edifícios e seus serviços permaneçam em uma condição segura; garantir uma boa condição de uso do edifício; assegurar as condições e requisitos estatutários de determinado edifício; executar ações que sejam necessárias para manter o valor físico dos edifícios; manter a qualidade do edifício.

Desta maneira, a manutenção preventiva é aquela programada para correr antes que haja a necessidade de reparo em um edifício. É desenvolvida por meio de uma programação que contenha datas pré-determinadas que obedecem a critérios técnicos determinados pelo fabricante e/ou fornecedor do material utilizado na construção de determinado edifício. Na manutenção preventiva deve-se registrar todas as atividades executadas durante a realização da mesma (CAMPOS et al., 2014). Boto (2014) ressalta a manutenção preventiva está aliada a um planejamento de intervenção que define a periodicidade da manutenção de maneira a diminuir o número de operações e por consequência os custos associados a este tipo de manutenção. Machado (2013) ressalta que, em um edifício este tipo de manutenção:

Requer um planejamento que integre os planos elaborados para cada componente do edifício com informação bem sintetizada e clara para quem vai realizar as atividades de 
manutenção, sendo que na sua elaboração deverão ser tidos em conta aspectos como: (i) a vida útil de cada componente; (ii) os níveis de qualidade, de desempenho e operacionalidade exigidos; (iii) as anomalias relevantes e seus mecanismos de degradação; (iv) as causas prováveis das anomalias; (v) a análise dos registros históricos das intervenções em componentes desse edifício e noutros similares; (vi) as recomendações técnicas do projeto e dos fabricantes/fornecedores; (vii) os custos de operação. (MACHADO, 2013)

A NBR 5674:2012 estabelece alguns requisitos para a realização dos serviços de manutenção, sendo que o primeiro é consideração dos aspectos construtivos (tipologia e o uso da edificação, tamanho e complexidade, localização e implicações do entorno). Segue-se, então, diretrizes que irão assegurar a preservação do desempenho, minimizando a depreciação patrimonial, estabelecendo e compartilhando informações importantes, além de determinar as responsabilidades de cada um dos envolvidos no processo de manutenção (PINTO, 2018).

Na pesquisa desenvolvida por Campos et al. (2014) que teve como objetivo elaborar "um plano de manutenção predial preventiva, dentro da realidade local", segundo a NBR 5674 (Manutenção de edificações) e NBR 14.037 (Manual de operação, uso e manutenção das edificações). Nesta pesquisa os autores destacaram as características da edificação pesquisada, os sistemas e seus componentes. Os sistemas da edificação pesquisada foram divididos em áreas a fins e áreas privadas, e posteriormente foram estabelecidas a periodicidade de manutenção dos mesmos. Nesta pesquisa, os autores concluíram que a manutenção preventiva leva a uma maior conservação dos imóveis, promove a conscientização dos proprietários e usuários, além de ajudar a diminuir os custos não planejados.

Em outra pesquisa desenvolvida por Saldanha (2017), a autora pesquisou uma empresa de revenda de carros e levantou as principais manifestações patológicas e sugeriu possíveis manutenções preventivas e ações que teriam evitado algumas manutenções corretivas que foram realizadas no local. A autora destacou algumas patologias: infiltrações nas paredes externas e internas, desgaste do telhado, defeitos no piso de madeira (desgaste), rompimento da lona da fachada principal, corrimão solto, banheiro impróprio para uso. Nesta pesquisa a autora constatou que $64 \%$ das patologias poderiam ser evitáveis caso fosse realizada a manutenção de caráter preventivo de maneira a manter as condições de uso, habitabilidade e segurança.

Ferreira (2018) realizou um estudo de campo com seis empresas em Curitiba/PR sobre a manutenção predial e constatou que as principais patologias apontadas pelas empresas estavam relacionadas às vedações das estruturas, havendo predomínio nos revestimentos externos, mais especificamente nas fachadas e apontou as seguintes patologias: "desagregações e destacamento de concreto, tratamento de fissuras, trincas, rachaduras, destacamentos de revestimentos de pastilhas, revitalizações de fachadas, preenchimentos de juntas de dilatação" e ressalta que essas patologias poderiam ser evitadas caso as empresas adotassem a manutenção preventiva. Na fala da autora a mesma expõe que: "as falhas dessas patologias e o porquê da ocorrência delas nesses serviços, estão relacionados à falta de manutenção preventiva, à especificação inadequada de materiais, ao uso de mão de obra não especializada, e também em relação ao tempo de execução dos serviços". Senise Filho (2018) "ressalta a importância da realização da manutenção preventiva de forma correta para que não seja necessária uma manutenção corretiva no futuro, que é um serviço com maior tempo de duração e de custo mais elevado". 


\section{Manutenção Corretiva}

A manutenção corretiva é aquela que se caracteriza por serviços imediatos com a intenção de permitir a continuidade do uso e evitar riscos ou prejuízo aos usuários de determinado edifício. Este tipo de manutenção é realizado após o aparecimento de uma patologia podendo ser de urgência, grande intervenção e pequena intervenção. A manutenção corretiva de urgência é realizada quando ocorre uma patologia que exige resolução imediata (GUERREIRO, 2013).

Este tipo de manutenção é um dos mais antigos e conservador e se caracteriza pela reatividade e por ações não planejadas ou programadas, sendo a menos recomendada. É uma manutenção utilizada mediante alguma falha, defeito, ou seja, quando ocorre algum problema no edifício ou em seus componentes. É uma manutenção que possui custos elevados devido a urgência. Outro problema está relacionado a falta de identificação total de patologias nos edifícios, ou não apontadas pelos usuários, que podem se agravar com o tempo, degradando e provocando o envelhecimento precoce do edifício, além de reduzir a vida útil do mesmo como um todo (equipamentos, máquinas e instalações) (FERREIRA, 2017). A NBR: 5674 destaca que:

A manutenção não planejada, caracterizada por serviços não previstos na manutenção planejada, incluindo a manutenção de emergência, caracterizada por serviços que exigem intervenção imediata para permitir a continuidade do uso das edificações ou evitar graves riscos ou prejuízos pessoais e patrimoniais aos seus usuários ou proprietários. (ABNT, 2012).

Villanueva (2015) destaca que esse tipo de manutenção é muito difícil de existir devido a imprevisibilidade de alguns problemas que podem acontecer em um edifício, porém ressalta que existem ações que podem reduzir a necessidade deste tipo de manutenção, como é o caso da existência e pessoal treinado para atuar de maneira rápida e eficiente nos defeitos possíveis. É um tipo de manutenção muito difundida pelo Brasil, que gera custos mais elevados quando comparado à manutenção preventiva e outros tipos de manutenção. É uma manutenção que pode ser classificada em duas formas distintas, conforme demonstra a figura 2. Assim, pode-se dizer que a manutenção corretiva é aquela que conserta quando quebra. É uma manutenção que, na maioria das vezes, necessita que seja paralisado total ou parcial de um sistema para ser desenvolvida (STUCKER, 2018).

\begin{tabular}{|c|l|}
\hline Estratégia Adotada & \multicolumn{1}{|c|}{ Característica } \\
\hline $\begin{array}{c}\text { Manutenção corretiva } \\
\text { planejada }\end{array}$ & $\begin{array}{l}\text { Correção que se faz em função de um un até pela } \\
\text { acompanhamento preditivo, detectivo, ou até } \\
\text { decisão gerencial de se operar até a falha. Esta } \\
\text { decisão, para ser eficaz, deve ser calcada em estudos } \\
\text { técnico-financeiros. Decide-se pela manutenção } \\
\text { corretiva porque, no equipamento ou componente } \\
\text { específico, o custo será menor que outros métodos. }\end{array}$ \\
\hline $\begin{array}{c}\text { Manutenção corretiva } \\
\text { não planejada }\end{array}$ & $\begin{array}{l}\text { Correção da falha de maneira aleatória, , ou seja, é a } \\
\text { manutenção atuando no momento da falha do do } \\
\text { equipamento, agindo de forma impulsiva. Caracteriza- } \\
\text { se pela ação, sempre após a ocorrência da falha, que } \\
\text { é aleatória, e sua adoção leva em conta fatores } \\
\text { técnicos e econômicos. }\end{array}$ \\
\hline
\end{tabular}

Figura 1: Classificação da manutenção corretiva. Fonte: Marques (2010, citado por VILLANUEVA, 2015). 


\section{Importância da manutenção preventiva e corretiva nas edificações}

A NBR: 5674 normatiza ações direcionadas à manutenção dos edifícios e nesta norma estão estabelecidos todos os tipos de manutenção, dentre estas estão a manutenção preventiva e corretiva (descrita como não planejada na norma). Independentemente do tipo, a manutenção poder ser conceituada como um conjunto de procedimentos desenvolvidos periodicamente nos sistemas, equipamentos e máquinas. O desenvolvimento destes procedimentos possui como objetivo manter os dispositivos em pleno funcionamento, garantindo que todas as funções sejam desempenhadas de maneira eficaz (ABNT, 2012).

A importância da manutenção é definida por Nunes et al. (2008, citado por COSTA, 2013):

Em linhas gerais, pode-se afirmar que toda evolução tecnológica dos equipamentos, processos e técnicas de manutenção, a necessidade de controles cada vez mais eficientes e de ferramentas de apoio à decisão, o desenvolvimento de estudos relativos ao desgaste e controle das falhas e suas consequências, a dependência de equipes treinadas e motivadas para enfrentar estes desafios, o desenvolvimento de novas técnicas, e, consequentemente, os custos de manutenção em termos absolutos e proporcionalmente às despesas globais, transformaram a gestão da manutenção em um segmento estratégico para o sucesso empresarial. (NUNES et al., 2008, citado por COSTA, 2013)

A manutenção caracteriza-se por um fluxo constante de serviços padronizados e periódicos, como: limpeza, lavagem, consertos, adequações, dentre outros. Costa et al. (2018) ressaltaram em seu trabalho que as edificações são passiveis de desgastes devido ao elevado trânsito de pessoas, o que ocasiona a necessidade de reparos para evitar que um simples problema se transforme em um caos para os usuários. "Para evitar este constrangimento, é necessário que este empreendimento implante um sistema de manutenção preventiva e corretiva", o que irá favorecer um ambiente seguro para seus usuários.

Tanto a manutenção preventiva quanto a corretiva são importantes para a preservação dos edifícios. A manutenção preventiva planeja a ação de manutenção antes que haja a necessidade de reparo. Neste tipo de manutenção é essencial que se planeje as ações com data e critérios técnicos, além do registro de todas as atividades realizadas. A manutenção corretiva volta-se para a reparação das anomalias ou falhas, podendo a mesma ser planejada ou não. Neste tipo de manutenção há a necessidade da paralisação parcial ou total das atividades para o desenvolvimento da ação (STUCKER, 2018).

Costa (2013) ressalta que é importante que se utilize de uma metodologia adequada de gestão do sistema de manutenção, o que colocará a função manutenção como um fator estratégico para a redução de custos totais de produção e não como um gasto adicional para o empreendimento.

\section{CONCLUSÕES}

Neste trabalho foi possível concluir que a manutenção de uma edificação é desenvolvida por meio de ações de limpezas, vistorias e reparos dos componentes e dos sistemas da obra. As ações de manutenção buscam garantir a funcionalidade dos equipamentos e instalações de forma que atenda ao processo de serviço e produção de maneira confiável, segura e com custos adequados.

Esta pesquisa teve como foco a manutenção preventiva e corretiva, onde concluiu-se que a manutenção preventiva é um tipo de manutenção onde as ações são previamente planejadas e a 
manutenção corretiva é realizada por meio de ações não planejadas, de maneira imediata, e tem como objetivo restaurar a capacidade funcional dos equipamentos ou dos sistemas que estão com problema.

Tanto a manutenção preventiva quanto à manutenção corretiva, são importantes para os edifícios, uma vez que ambas possuem como objetivo manter dos dispositivos dos edifícios em funcionamento. Desta maneira, sugere-se que mais estudos sejam desenvolvidos sobre o tema manutenção nos edifícios, uma vez que os mesmos trazem informações relevantes e que podem contribuir para a conscientização de profissionais e gestores sobre a importância de planejar um bom sistema de manutenção.

\section{REFERÊNCIAS}

ABNT. Associação Brasileira de Normas Técnicas. NBR-5674: Manutenção de Edificações: Procedimentos. Norma técnica. Rio de Janeiro: ABNT, 2012.

ABNT. Associação Brasileira de Normas Técnicas. ABNT NBR 15.575: Guia para arquitetos na aplicação da norma de desempenho. CAU/BR Conselho de Arquitetura e Urbanismo do Brasil. Rio de Janeiro: ABNT, 2013.

BOTO, M. G.. Plano de manutenção de fachadas em edifícios na zona costeira. Dissertação (Mestrado em Engenharia Civil) - Universidade Fernando Pessoa, Porto, 2014.

CARDOSO, J.. Diretrizes para elaboração de programas de manutenção predial, com ênfase em estruturas, instalações elétricas e hidráulicas. Dissertação (Mestrado em Habitação: planejamento e Tecnologia) - Instituto de Pesquisas Tecnológicas do Estado de São Paulo, São Paulo, 2016.

COELHO, F. M. F.. Manutenção e reabilitação de edifícios de saúde. Dissertação (Mestrado em Engenharia Civil) Instituto Superior de Engenharia de Lisboa, Lisboa, 2016.

COSTA, M. A.. Gestão estratégica da manutenção: uma oportunidade para melhorar o resultado operacional. Monografia (Bacharelado em Engenharia da Produção) Universidade Federal de Juiz de Fora, Juiz de Fora, 2013.

COSTA, A. L. B.; BALDUINO, A. R.. The Importance of Preventive and Corrective Maintenance in Works. International Journal of Advanced Engineering Research and Science, v.5, n.5, 2018. DOI:

http://dx.doi.org/10.22161/ijaers.5.5.10

CRUZ, A. F. R.; BARBOSA, M. T. G.; CASTANÕN, J. A. B.. Análise do processo de manutenção em diferentes sistemas construtivos no Brasil. REUCP, Petrópolis, v.11, n.1, p.33-43, 2017.

DONATO, F. C.; MARTINS, I. DE C.; VEIRA, L. H. L.; AMARAL, I. B. C.; DOS REIS, A. B.. Manifestações patológicas relacionadas a revestimentos cerâmicos de fachadas na cidade de Ipatinga/MG. Revista Tecnológica, v.27, n.1, p.82 94, 2019. DOI:

http://doi.org/10.4025/revtecnol.v27i1.45233

FERREIRA, F. M. C.. Modelo para gestão de manutenção predial em universidades públicas: caso das IFES mineiras. Tese (Doutorado em Ciências da Engenharia Civil) Universidade Federal de Ouro Preto, Ouro Preto, 2017.
FERREIRA, R. R.. Manutenção predial: uma análise das principais patologias. Monografia (Especialização em Gerenciamento de Obras) - Universidade Tecnológica Federal do Paraná, Curitiba, 2018.

GENTILI, Y. V.. Gerenciamento orientado da manutenção predial em edifícios privados: um estudo de caso em Natal/RN. Monografia (Bacharelado em Engenharia Civil) Universidade Federal do Rio Grande do Norte, Natal, 2018.

GUERREIRO, R. P. R.. Metodologia de manutenção de edifícios. Dissertação (Mestrado em Engenharia Civil) Faculdade de Engenharia Universidade do Porto, Porto, 2013.

MINAYO, M. C. S.. Análise qualitativa: teoria, passos e fidedignidade. Ciênc. Saúde Coletiva, v.17, n.3, p.621-626, 2012. DOI: http://doi.org/10.1590/S141381232012000300007

QUEIROZ, E. O. C.. Gestão da manutenção predial no setor público a partir do estudo de caso do edifício da escola de ciências e tecnologia/UFRN. Monografia (Bacharelado em Engenharia Civil) - Universidade Federal do Rio Grande do Norte, Natal, 2018.

SALDANHA, N. F.. Estudo de caso: comparativo entre manutenção predial corretiva e preventiva em um estabelecimento comercial na cidade do automóvel. Monografia (Bacharelado em Engenharia Civil) -Centro Universitário de Brasília, Brasília, 2017.

SANTOS, A. F. P. C.. Manutenção predial e reabilitação de edifícios. Dissertação (Mestrado em Engenharia Civil) Universidade da Beira Interior Engenharia, Covilhão, 2017.

SENISE FILHO, R. W. G.. Estudo de caso: aplicação de modelo de manutenção predial para edificação no setor comercial de Brasília. Monografia (Bacharelado em Engenharia Civil) Faculdade de Tecnologia e Ciências Sociais aplicadas, Brasília, 2018.

STUCKER, K.. Plano de manutenção em condomínio residencial. Monografia (Bacharelado em Engenharia de Produção Elétrica) - Universidade Federal de Santa Catarina, Florianópolis, 2018.

VILLANUEVA, M. M.. A importância da manutenção preventiva para o bom desempenho da edificação. Monografia (Bacharelado em Engenharia Civil) Universidade Federal do Rio de Janeiro, Rio de Janeiro, 2015.

A CBPC - Companhia Brasileira de Produção Científica (CNPJ: 11.221.422/0001-03) detém os direitos materiais desta publicação. Os direitos referem-se à publicação do trabalho em qualquer parte do mundo, incluindo os direitos às renovações, expansões e disseminações da contribuição, bem como outros direitos subsidiários. Todos os trabalhos publicados eletronicamente poderão posteriormente ser publicados em coletâneas impressas sob coordenação da Sustenere Publishing, da Companhia Brasileira de Produção Científica e seus parceiros autorizados. Os (as) autores (as) preservam os direitos autorais, mas não têm permissão para a publicação da contribuição em outro meio, impresso ou digital, em português ou em tradução. 